\title{
The Effect of Molecular Sieves on the Thermolysis of Cedar in a Tubular Furnace Reactor
}

\author{
M. Nakayasu, N. Morita, and H. Nakagome
}

\begin{abstract}
Japanese cedar was pyrolyzed using a tubular furnace reactor with added molecular sieves in an attempt to increase the quantity of methane produced. A predetermined mixture of molecular sieves and cedar were heated in the tubular furnace reactor up to $700{ }^{\circ} \mathrm{C}$ under a nitrogen atmosphere. The flammable gas and the residual substance provided by the thermolysis were examined. The yield of the $\mathrm{CH}_{4}$, which is a combustible gas generated from thermolysis, was increase by adding $5 \mathrm{~A}$ molecular sieves. In addition, the tubular furnace was found to cause complete thermolysis.
\end{abstract}

Index Terms-Thermal decomposition, tubular reactor, biomass, molecular sieves.

\section{INTRODUCTION}

Increasing demand for fossil fuel has led to a global energy crisis. Reserves of fossil fuels are limited and developments to improve the efficient production of renewable fuels are important [1]. Fossil fuels have played an important role in supplying fuel for transportation and have contributed to greenhouse gas (GHG) discharge that causes considerable environmental problems [2]. The 196 countries that participated in the United Nations Climate Change Conference of 2015 agreed to restrain the rise of the average global temperature to less than $2{ }^{\circ} \mathrm{C}$ by decreasing GHG discharge. The Japanese government set a target of decreasing GHG discharge by $26 \%$ of the 2013 level by 2030 .

Japan had 54 nuclear power plants as of February, 2011 that contributed $31.3 \%$ of the national power supply, with fossil fuels generating $63.1 \%$, waterpower $5.1 \%$, and other renewable energy sources contributing $0.5 \%$. However, the majority of these nuclear power plants have been shut down and remain offline following the Great East Japan Earthquake, and there is considerable need to discover an alternative energy to replace the lost energy production. Biomass has attracted increasing global interest over the past 20 years as a potential alternative to fossil fuels that can provide useful products by thermochemical conversion of renewable resources through thermolysis or gasification [3]-[5]. One of the best solutions to lower GHG emission is to use materials that are comprised of carbon as substitutes for fossil fuels, such as wood and wood processing waste, energy crops, agriculture and organic wastes, materials derived from wastes, and sewage sludge [6]-[10]. In addition, using biomass for energy supply is an attractive substitute for fossil fuels

Manuscipt received October 25, 2016; revised December 25, 2016.

The authors are with Chiba University, Japan (e-mail: agha1130@chiba-u.jp, nakagome@chiba-u.jp). because it does not contribute a carbon footprint and the energy generated is carbon neutral [6].

Japan has forests that account for approximately $67 \%$ of the countries land area, which could be an abundant source of biomass for thermochemical conversion to fuels. This biomass mainly consists of extracts (tannins, fatty acids, and resins), inorganic salts, and three main polymers (cellulose [9]-[13], hemicellulose [14]-[16], and lignin [17]-[19]). These three components are broken down by thermolysis at different temperatures and speeds. Cellulose, hemicellulose, and lignin decompose slowly over a wide temperature range of 280 to $600{ }^{\circ} \mathrm{C}$. Degradation of these polymers occurs relatively fast at low temperatures between 200 and $350{ }^{\circ} \mathrm{C}$ when pyrolyzed in the absence of oxygen to form char, liquid and gas components [2], [20], [21]. Product distribution and yield are affected by temperature and the speed of pyrolysis [22], [23]. High temperature thermolysis decreases the proportion of char and increases the yield of the liquid and gas generated [10], [24], [25]. On the other hand, gas production and the yield of the char decrease with low temperature thermolysis, and the liquid component increases. Gasification of the biomass maximizes gaseous products under conditions that minimize char and ash [26]-[28]. Dehydration and de-carboxylation can be promoted by the use of pro-zeolite catalysts at atmospheric pressure [29], [30]. Molecular sieves are reported as effective cracking catalysts along with other zeolites [31]. These zeolite are an attractive low-cost substitute for traditional catalysts used in high pressure hydrogenation biomass thermolysis [29], [32], [33].

We have previously reported that the use of molecular sieves, which are a zeolite catalyst, for the pyrolytic decomposition of cedar increased the quantity of the flammable gas at the low temperature $450{ }^{\circ} \mathrm{C}$ [34]. In this study, the potential to increase thermolytic production of methane from cedar using catalytic molecular sieves in a tubular furnace reactor was investigated.

\section{PRocedure}

\section{A. Materials}

Japanese cedar wood chips were sourced from Sanbu, Chiba, Japan (SAMBU SUGI) and dried before use. Molecular sieves 3A 1/16 (diameter 1.4-2.0 mm), 5A 1/16 (diameter 1.4-2.0 mm), and 13X 1/16 (diameter 1.4-2.0 mm) were purchased from Wako Pure Chemical Industries. A predetermined quantity of molecular sieves was added to a 20-g sample of cedar and mixed for each experimental condition (Table I). Cedar alone was used as a control (condition I) and sea sand was used as an additive to establish 
if the influence of dispersive granules on the yields and distribution of products (condition VIII).

TABLE I: EXPERIMENTAL CONDITIONS

\begin{tabular}{ll}
\hline \hline \multicolumn{2}{c}{ Condition of sample } \\
\hline \hline I & Cedar 20g \\
II & Cedar 20g + Molecular sieves 3A 20g \\
III & Cedar 20g + Molecular sieves 5A 20g \\
IV & Cedar 20g + Molecular sieves 13X 20g \\
V & Cedar 20g + Molecular sieves 3A 10g \\
VI & Cedar 20g + Molecular sieves 5A 10g \\
VII & Cedar 20g + Molecular sieves 13X 10g \\
VIII & Cedar 20g + Sea sand 20g \\
\hline \hline
\end{tabular}

\section{B. Verification of the Reactor}

Previous pyrolysis experiments in a glass reactor at the low temperature range of 400 to $600{ }^{\circ} \mathrm{C}$ resulted in incomplete degradation, with a central part of the sample that was stable to thermolysis. Therefore, we switched from a glass reactor to a tubular furnace reactor, which heats the whole sample uniformly. When thermolysis was performed at a setting of $700{ }^{\circ} \mathrm{C}$, the median temperature was 600 to $800{ }^{\circ} \mathrm{C}$, and thermolysis occurred with a stable state throughout the temperature range.

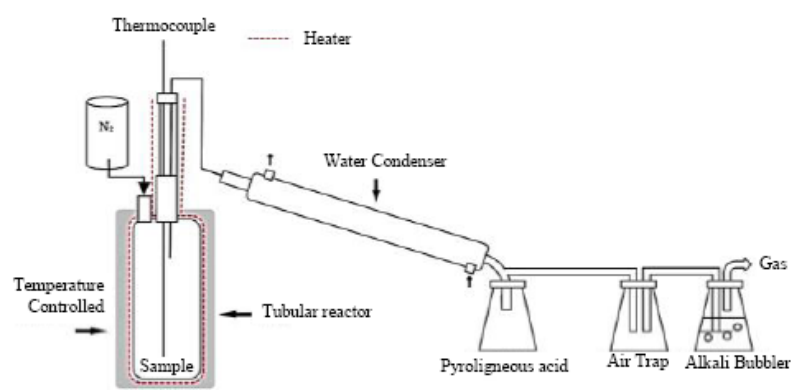

Fig. 1. Experimental apparatus.

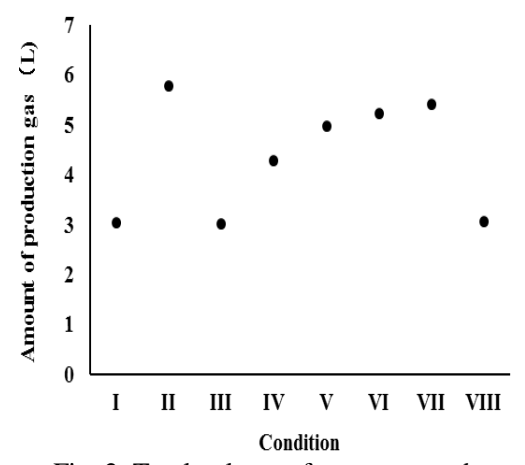

Fig. 2. Total volume of gas generated.

\section{Experimental Apparatus Procedures}

The experimental device used in this study is depicted in Fig. 1. A mixed sample of approximately $20 \mathrm{~g}$ of cedar and molecular sieves was placed in the tubular furnace reactor. Nitrogen gas was passed over the sample for $60 \mathrm{~min}$ at a flow of $50 \mathrm{~mL} / \mathrm{min}$ to remove oxygen from the reactor before heating. The temperature rise was held below $10{ }^{\circ} \mathrm{C} / \mathrm{min}$ and increased to $700{ }^{\circ} \mathrm{C}$ then heating was ceased and the reactor allowed to cool to room temperature. The non-condensable gas generated during thermolysis was collected in a gas pack after passing through an alkaline water solution $(0.1 \mathrm{~mol} / \mathrm{L}$ sodium hydroxide water solution). All the gas collected in the gas pack was assumed to be generated by the pyrolysis and the gas and residual substance in a tubular furnace reactor were analyzed for each sample.

\section{Analysis}

The resolution gas generated was qualitatively and quantitatively analyzed using a SHIMAZU GC2014FID. The cedar was observed before and after thermolysis by energy dispersive spectroscopy (EDS, BRUKER D2FAHSER) attached to an electron microscope (Hitachi high technology TM3030) using BURUKER QUANTAX energy dispersion type X-rays analysis. A cedar sample was combusted at a temperature of $800{ }^{\circ} \mathrm{C}$ and total nitrogen, carbon, and hydrogen measured using a SUMIGRAPH NCH-22A. The cedar was $1.5 \%$ nitrogen, $62.7 \%$ carbon, and $8.9 \%$ hydrogen by weight [34].

\section{RESULTS AND DISCUSSION}

\section{A. Gas Generation}

The quantity of gas generated by thermolysis for each condition is shown in Fig. 2. The quantity of gas generated did not increase when unreactive granules were added to the cedar (condition I vs. condition VIII).

The amount of methane produced is shown in Fig. 3. Methane production increased with the addition of molecular sieves (conditions II-VII), and we infer that the molecular sieves have a catalytic effect. The yield of methane generated as a proportion of the total gas produced is shown in Fig. 4. The total gas produced is similar for conditions I and III (Fig. 2 ), but the methane yield of condition III is approximately 1.7 times that of condition I, demonstrating the improved efficiency of the gasification to useful products with molecular sieves.

The amount of carbon dioxide produced for each mixture is shown in Fig. 5. Production of carbon dioxide was lowest with conditions III and VI for the samples with molecular sieves, suggesting 5A molecular sieves are better at promoting thermolysis to form methane.

The yield of carbon dioxide as a proportion of the total gas produced is shown in Fig. 6. Unlike for thermolysis undertaken in a glass reactor, no pyroligneous acid was collected from the pyrolysis reactions in the tubular furnace reactor, suggesting that a temperature of $700{ }^{\circ} \mathrm{C}$ caused complete gasification.

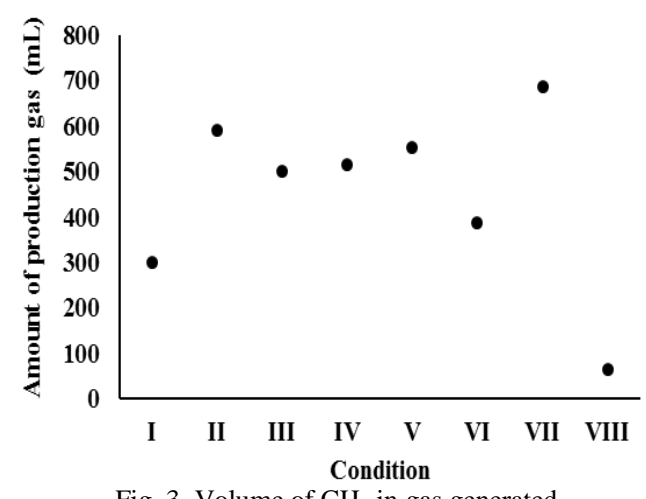

Fig. 3. Volume of $\mathrm{CH}_{4}$ in gas generated. 
The EDS images of cedar with an equal amount of $5 \mathrm{~A}$ molecular sieves before (condition 0) and after pyrolysis (condition III) are shown in Fig. 7(a) and (b), respectively.

In addition, Fig. 8 shows the proportion of carbon surface area for all conditions.

The carbon surface area increased after thermolysis for all conditions compared with condition 0 . This shows that thermolysis had occurred for all the samples heated to $700{ }^{\circ} \mathrm{C}$ with or without the addition of molecular sieves.

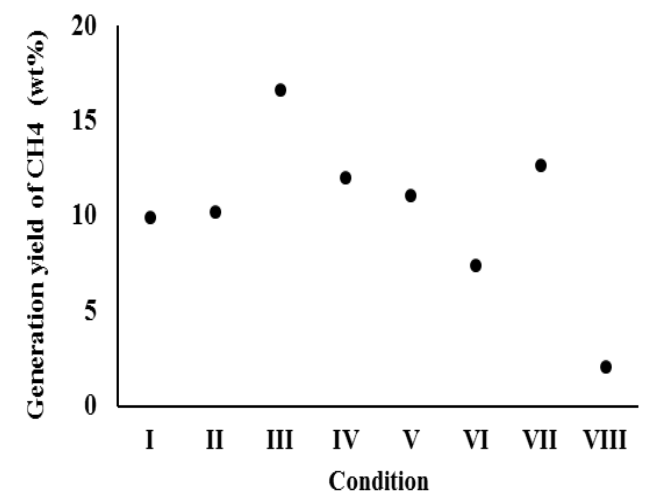

Fig. 4. Yield of $\mathrm{CH}_{4}$.

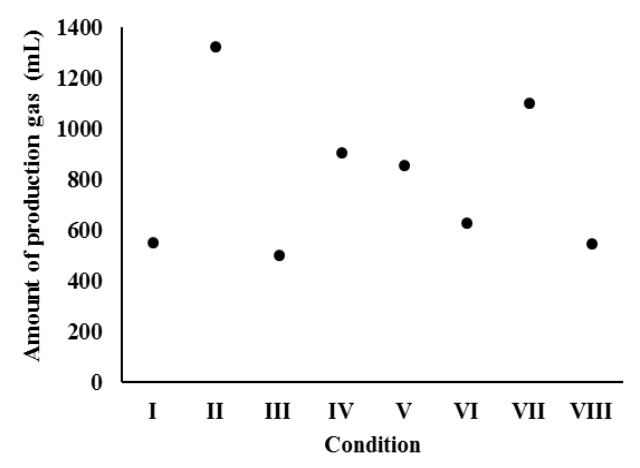

Fig. 5. Volume of $\mathrm{CO}_{2}$ in gas generated.

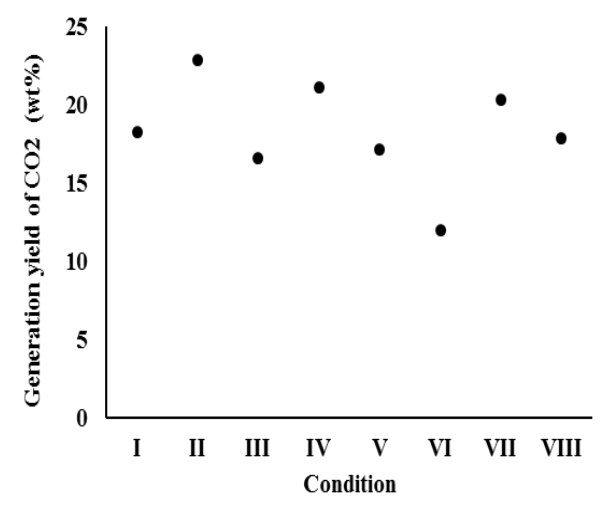

Fig. 6. Yield of $\mathrm{CO}_{2}$.

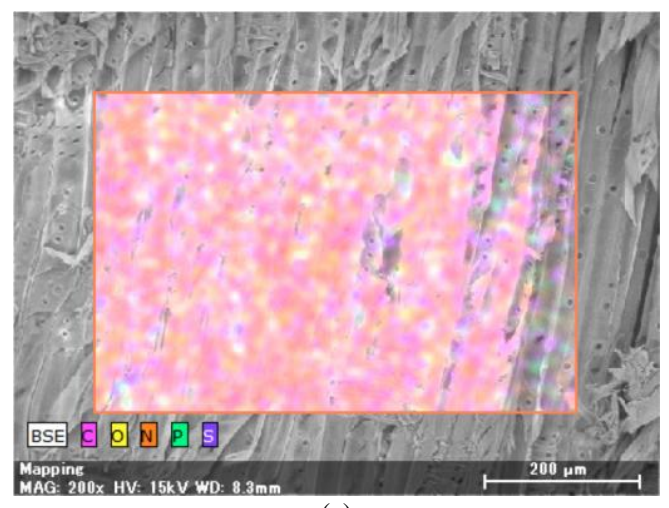

(a)

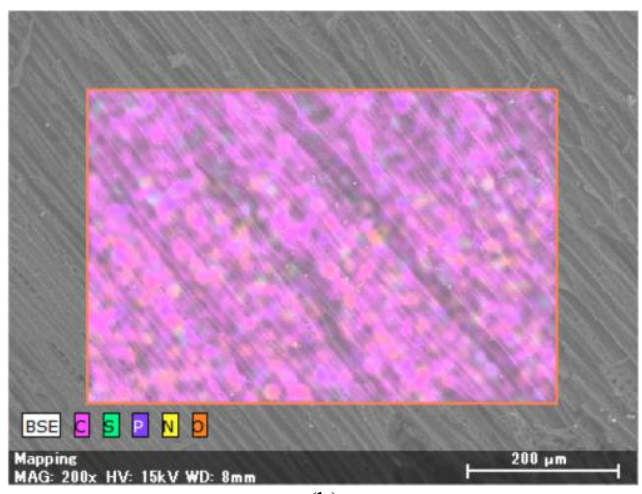

(b)

Fig. 7. Energy dispersive spectroscopy images of cedar (a) before and (b) after pyrolysis.

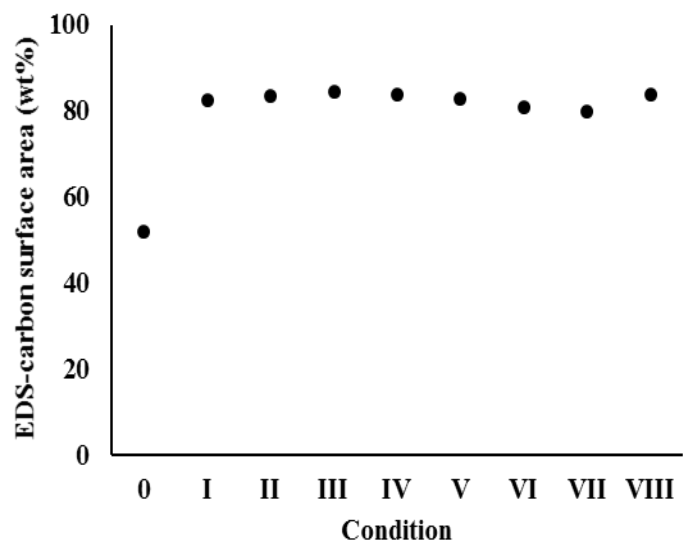

Fig. 8. EDS-carbon surface area.

\section{CONCLUSION}

In this study, molecular sieves were added to samples of cedar and pyrolyzed using a tubular furnace reactor.

The cedar was degraded to gas and residue and these were examined.

Using molecular sieves minimized carbon dioxide emission compared with thermolysis of cedar only and the yield of methane reached a maximum of $16.6 \%$.

From the EDS images, an increase in carbon surface area can be observed after thermolysis in all conditions. Therefore, it is presumed that pyrolysis is performed completely at $700{ }^{\circ} \mathrm{C}$.

\section{ACKNOWLEDGMENT}

This work was supported by Mr. Katsunori Suzuki of Tokyo Metropolitan Tama High School of Science and Technology, Japan. We thank Ms. Yuumi Awashima, Ms. Mami Nishi, Ms. Keiko Ueda, Ms. Mai Miyauchi and Ms. Arisa Kato.

\section{REFERENCES}

[1] I. Ahmed and A. K. Gupta, "Characteristic of hydrogen and syngas evolution from gasification and pyrolysis of rubber," International Journal of Hydrogen Energy, vol. 36, pp. 4340-4347, 2011.

[2] S. Ren, H. Lei, L. Wang, Q. Bu, S. Chen, and J. Wu, "Thermal behaviour and kinetic study for woody biomass torrefaction and torrefied biomass pyrolysis by TGA," Biosystems Engineering, vol. 116, pp. 420-426, 2013.

[3] C. Couhert, J. M. Commandre, and S. Salvador, "Failure of the component additivity rule to predict gas yields of biomass in flash 
pyrolysis at 950C," Biomass and Bioenergy, vol. 33, pp. 316-326, 2009

[4] D. Ferdous, A. K. Dalai, R. W. Thring and N. N. Bakhshi, "Production of $\mathrm{H}_{2}$ and medium Btu gas via pyrolysis of lignins in a fixed-bed reactor," Fuel Process Technol, vol. 70, pp. 9-26, 2001.

[5] L. Zhang, C. Charles, and P. Champagne, "Overview of recent advances in thermochemical conversion of biomass," Energy Convers Manage, vol. 51, pp.969-982, 2010

[6] M. Wilk, A. Magdziarz, I. Kalemba, and P. Gara, "Carbonisation of wood residue into charcoal during low temperature process," Renewable Energy, vol. 85, pp. 507-513, 2016.

[7] A. Demirbas, "Combustion Characteristics of different biomass fuels, prog," Energy Combust, vol. 30, pp. 219-230, 2004.

[8] B. M. Jenkins, L. L. Baxter, T. R. Miles Jr., and T. R. Miles, "Combustion properties of biomass," Fuel Process Technology, vol. 54, pp. 17-46, 1998.

[9] F. X. Collard and J. Blin, "A review on pyrolysis of biomass constituents: Mechanisms and composition of the products obtained from the conversion of cellulose, hemicelluloses and lignin," Renewable and Sustainable Energy Reviews, vol. 38, pp. 594-608, 2014.

[10] C. Couhert, J. M. Commandre, and S. Salvador, "Is it possible to predict gas yields of any biomass after rapid pyrolysis at high temperature from its composition in cellulose, hemicellulose and lignin?," Fuel, vol. 88, pp. 408-417, 2009

[11] R. P. Pushkaraj, L. D. Dustin, H. S. Brent, and C. B. Robert, "Distinguishing promary and secondary reactions of cellulose pyrolysis," Bioresource Technology, vol. 102, pp. 5265-5269, 2011.

[12] D. Meier and O. Faix, "State of the art of applied fast pyrolysis of lignocellulosic materials - A review," Bioresource Technology, vol. 68, pp. 71-77,1999.

[13] M. Jahirul, M. Rasul, A. Chowdhury, and N. Ashwath, "Biofuels production through biomass pyrolysis - A technological review, Energies, vol. 5, pp. 4952-5001, 2012.

[14] D. Mohan, C. U. Pittman, and P. H. Steele, "Pyrolysis of wood/biomass for biooil: A critical review," Energy Fuels, vol. 20, pp. 848-889, 2006.

[15] Q. Ahang, J. Chang, T. Wang, and Y. Xu, "Review of biomass pyrolysis oil properties and upgrading research," Energy Conversion Management, vol. 48, pp. 87-92, 2007.

[16] D. B. Colomba, "Modeling chemical and physical processes of wood and biomass pyrolysis," Progress in Energy and Combustion Science, vol. 34, pp. 47-90, 2008.

[17] A. V. Bridgwater, "Review of fast pyrolysis of biomass and product upgrading," Biomass and Bioenergy, vol. 38 pp. 68-94, 2012.

[18] J. N. Saddler and D. J. Gregg, "Biomass for energy and the enviroment," in Proc. Ninth European Bioenergy Conference, pp. 349-355, 1996

[19] A. Heidari, R. Stahl, H. Younesi, A. Rashidi, N. Troeger, and A. A. Ghoreyshi, "Effect of process conditions on product yield and composition of fast pyrolysis of Eucalyptus grandis in fluidized bed reactor," Journal of Industrial and Engineering Chemistry, vol. 20, pp. 2594-2602, 2014.

[20] M. K. Bahng, C. Mukarakate, D. J. Robichaud, and M. R. Nimlos, "Current technologies for analysis of biomass thermochemical processing: A review," Analytica Chimica Acta, vol. 651, pp. 117-138, 2009

[21] G. L. Henriksson and T. Ljungberg, "Pulp and paper chemistry and technology, Book 1," Wood Chemistry and Wood Biotechnology, pp. $125-148,2007$

[22] S. N. Naik, V. V. Goud, P. K. Rout, and A. K. Dalai, "Production of first and second generation biofuels: A comprehensive review," Renewable and Sustainable Energy Reviews, vol. 14, pp. 578-597, 2010.
[23] H. B. Goyal, D. Seal, and R. C. Saxena, "Bio-fuels from thermochemical conversion of renewable resources: A review," Renewable Sustainable Energy Reviews, vol. 12, pp.504-517, 2008

[24] S. Li, S. Xu et al., "Fast pyrolysis of biomass in free-fall reactor for hydrogen-rich gas," Fuel Processing Technology, vol. 85, pp.1201-1211, 2004

[25] R. Zanzi, K. Sjöström et al., "Rapid high-temperature pyrolysis of biomass in a free-fall reactor," Fuel, vol. 75, no. 5, pp. 545-550, 1996.

[26] S. Yaman, "Pyrolysis of biomass to produce fuels and chemical feedstocks," Energy Conversion and Management, vol. 45, pp. 651-671, 2004.

[27] A. Demirbas, "Gaseous products from biomass by pyrolysis and gasification. Effect of catalyst on hydrogen yield," Energy Conv Manage, vol. 43, pp.897-909, 2002.

[28] A. Demirbas, "Biomass resource facilities and biomass conversion proceesing for fuels and chemicals." Energy Conv Manage, vol. 42, pp.1357-1378, 2001

[29] P. T. Williams and P. A. Horne, "Analysis of aromatic hydrocarbons in pyrolytic oil derived from biomass," Journal of Analyrical and Applied Pyrolysis, vol. 31, pp. 37, 1995.

[30] T. Stoikos, in A. V. Bridgwater and G. Grassi, Biomass Pyrolysis Liquids, Upgrading and Utilisation, Elsevier Applied Science, London 1991,

[31] J. B. Gujar, M. A. Chaudhari, D. S. Kawade, and M. S. Shingare, "Molecular sieves: An efficient and reusable catalyst for multi-component synthesis of dihydropyrano [2,3-C]pyrazole derivatives," Tetrahedron Letters, vol. 55, pp. 6030-6033, 2014.

[32] A. V. Bridgwater and M. L. Cottam, Energy Fuels, vol. 6, no. 2, pp. 113-120, 1992.

[33] E. Churin, Energy: Catalytic Treatment of Pyrolysis Oils, Cat. No. CD-NA-12480-EN-C, The Commission of the European Communities, Luxemboug, 1990.

[34] M. Nakayau, N. Morita, Y. kawabata, T. Wajima and H. Nakagome, "The effect of molecular sieve addition on the thermal decomposition of Japanese cedar," IJFE, 2016.

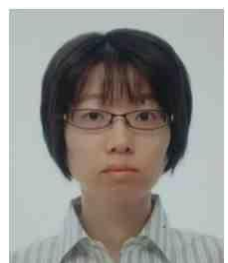

Masami Nakayasu was born in 1976. She studied chemical and environmental engineering at Chuo University Faculty of Science and Technology and graduated in 2001. She is now studying at the Department of Urban Environment System at Chiba University, Japan.

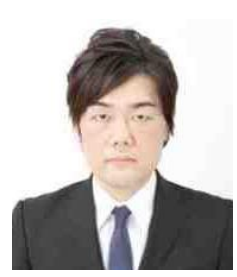

Naoyuki Morita was born in Japan in 1977. He graduated from Chiba University, Japan, in 2011 and acquired a doctorate from Chiba University in 2016.

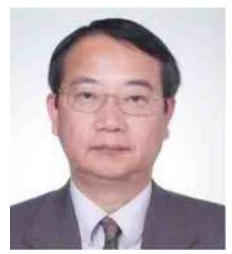

Hideki Nakagome was born in Japan in 1951. He is a professor at Chiba University, Japan. He acquired a doctorate from Tokyo University. His specializes in environmental engineering and mechanical engineering. 